\title{
Nitrogen Doped Graphene as Potential Material for Hydrogen Storage
}

\author{
Arjunan Ariharan, Balasubramanian Viswanathan*, Vaiyapuri Nandhakumar \\ National Centre for Catalysis Research, Indian Institute of Technology Madras, Chennai, India \\ Email: *bvnathan@iitm.ac.in
}

How to cite this paper: Ariharan, A., Viswanathan, B. and Nandhakumar, V. (2017) Nitrogen Doped Graphene as Potential Material for Hydrogen Storage. Graphene, 6, 41-60.

https://doi.org/10.4236/graphene.2017.62004

Received: March 20, 2017

Accepted: April 27, 2017

Published: April 30, 2017

Copyright $\odot 2017$ by authors and Scientific Research Publishing Inc. This work is licensed under the Creative Commons Attribution International License (CC BY 4.0).

http://creativecommons.org/licenses/by/4.0/

\begin{abstract}
The nitrogen doped graphene was synthesized by hydrothermal route utilizing 2-Chloroethylamine hydrochloride as nitrogen precursor in the presence of graphene oxide (GO). Nitrogen-doped graphene material is developed for its application in hydrogen storage at room temperature. Nitrogen doped graphene layered material shows $\sim 1.5 \mathrm{wt} \%$ hydrogen storage capacity achieved at room temperature and 90 bar pressure.
\end{abstract}

\section{Keywords}

Carbon Materials, Hydrogen Storage, Graphene, Heteroatom Doped Graphene, Nitrogen Doped Graphene, Hydrogen Storage Capacity, The Storage Capacity Observed Is Comparable to Other Carbon Materials

\section{Introduction}

The low-cost, environmentally acceptable and superior energy storage materials have been under constant search in recent times [1] [2]. The concern for green energy sources and over utilization of fossil fuels has prompted in creating hydrogen energy from renewable sources [3]. Every one of the three components of hydrogen economy, namely, generation, storage and the application has received attention [3] [4]. The first step in developing novel and nanostructured materials is in advanced stage in energy research. The second step is reversible hydrogen storage in suitable materials or adsorbed on appropriate surfaces which require several issues to be solved [5]. A particularly significant application is in hydrogen-fueled vehicles [6]. The storage capacity for possible commercial utilization of hydrogen as energy source is $6.5 \mathrm{wt} \%$ as postulated by US-DOE (Department of energy) [7]. The US-department of energy has challenged energy storage research scientists to accomplish onboard vehicle hydrogen storage systems with $5.5 \mathrm{wt} \%$ hydrogen in 2020 with the ultimate target of 
$7.5 \mathrm{wt} \%$ hydrogen [8]. High surface area adsorbents such as porous carbon materials, metal-organic frameworks, and porous polymers are considered and assessed for this application [7] [9]. No candidate till today has possibly reached the US-DOE targets for hydrogen storage. Any figure up to $67 \mathrm{wt} \%$ has been reported as storage capacity in solids particularly in carbon based materials [1] [2] [10] [11]. Obviously carbon nanomaterials including carbon nanotubes, fullerene and its derivatives, porous carbon and graphene have been applied in energy storage applications [12] [13] [14]. Carbon materials have been widely investigated for hydrogen storage due to their well-developed porosity, chemical and physical properties [15]. It was reported that the favorable pathway of hydrogen absorption in carbon materials is dissociation and chemisorption on the carbon sites and in particular isolated hydrogen is reasonably easier to diffuse on the carbon materials [16]. Modifying the carbon surface has been considered as one of the techniques for accomplishing higher hydrogen storage capacity. In spite of the fact that the addition of metal or metal oxides improves the hydrogen storage capacity to certain extent, the retrieval of hydrogen requires higher temperatures. The loading of metals and intermetallics to the hydrogen storage materials adversely affects the storage capacity and the reversibility of the hydrogen [17] [18] [19]. For decades graphitic nanocarbon is remained at the frontier of materials as promising functional materials [20]. In recent years, the family of carbon materials studied for hydrogen storage properties was extended to include graphene. Graphene, a one-atom layer of graphite, has a particular two-dimen- sional (2D) structure; it is utilized as a potential material for energy conversion and storage because of its high conductivity and charge bearer versatility, high specific surface area, high transparency and extraordinary mechanical strength [12] [21] [22] [23] [24] [25]. On the other hand, graphene is an attractive medium for hydrogen storage for the reason that it is readily available also in large quantities and potentially at low cost. These materials have been explored for potential applications in energy storage, catalysis and sensing [17] [21] [23] [26] [27] [28].

The possibility of preparation of graphene materials in various structures and phases enhances the application in hydrogen storage [29] [30] [31] [32]. One of the possibilities to enhance the hydrogen storage capacity in graphene material is to incorporate an active site on a graphene that is to substitute carbon atom by another element. The doping elements include $\mathrm{N}$ and $\mathrm{B}$, however doping with $\mathrm{P}$ and S have also been reported [33]-[44]. It has been proposed that heteroatom might be the alternate active centers for hydrogen activation and this activated hydrogen might move to the carbon surface by spill over [45]. As of late, materials with an assortment of morphologies that incorporate heteroatom have been pursued after for the reason of their unexpected hydrogen adsorption properties [37] [46] [47] [48] [49] [50]. At the same time nitrogen-doped carbonaceous materials have been investigated for energy storage applications. A nitrogen doped carbon catalyst with low price, high activity and fabulous durability has attracted numerous research efforts and is currently becoming one of the hot 
topics in the fuel cell field [51] [52] [53]. However, most of the compensating positive charge is distributed on the adjacent carbon atoms, which create the net positive charge centers on the adjacent carbon atoms to readily facilitate carbon surface to enhance the hydrogen adsorption property [54] [55].

In this study, we report an approach to realize the synthesis of heteroatom $(\mathrm{N})$ doped graphene material at a large scale by stepwise hydrothermal reaction that takes place at low temperature $\left(180^{\circ} \mathrm{C}\right)$ under ambient pressure in an autoclave followed by thermal annealing at $\left(500^{\circ} \mathrm{C}\right)$ of 2-Chloroethylamine hydrochloride as source of nitrogen coordinated with graphitic oxide (GO) under an inert atmosphere. The structural, chemical, morphological and textural characteristics of the prepared materials have been examined by different characterization methods. Besides the hydrogen storage capacity of the nitrogen doped graphene material is also reported.

\section{Materials and Methods}

\subsection{Materials}

Graphite powder (Extra pure), Sulfuric acid $98 \%\left(\mathrm{H}_{2} \mathrm{SO}_{4}\right)$, Sodium nitrate $99 \%$ $\left(\mathrm{NaNO}_{3}\right)$, Potassium permanganate $99.5 \%\left(\mathrm{KMnO}_{4}\right)$, Hydrogen peroxide $30 \%$ purified $\left(\mathrm{H}_{2} \mathrm{O}_{2}\right)$ and 2-Chloroethylamine hydrochloride (99\%) were purchased from Sigma Aldrich and used without further purification. Deionized (DI) water was used in all the experiments.

\subsection{Experimental Method}

\subsubsection{The Graphitic Oxide Was Synthesized as Follows}

Graphitic Oxide (GO) were synthesized from graphite by a modified Hummers method [56] Briefly, graphite powder (2.5 g) was taken into a beaker added 50 $\mathrm{mL}$ concentrated sulfuric acid $\left(\mathrm{H}_{2} \mathrm{SO}_{4}\right)$ under vigorous agitation in an ice bath. Afterwards, sodium nitrate $(2.0 \mathrm{~g})$ and potassium permanganate $(6.0 \mathrm{~g})$ were slowly added in a sequence. Then, the mixture was transferred into a water bath and kept at $35^{\circ} \mathrm{C}$ for 2 hour. After that, $100 \mathrm{~mL}$ of distilled water was slowly added, causing a temperature rise to $98^{\circ} \mathrm{C}$. Later, $140 \mathrm{~mL}$ of $4 \% \mathrm{H}_{2} \mathrm{O}_{2}$ was dropped into the reaction system. Finally, the product was washed with distilled water for three times. The acquired solid was dried in vacuum at $50^{\circ} \mathrm{C}$ for 48 hours.

\subsubsection{The Nitrogen-Doped Graphene Material Was Synthesized as Follows}

Typically, $2 \mathrm{~g}$ of Graphitic oxide was taken into a beaker and was diluted with 50 $\mathrm{mL}$ of deionized water then $6.5 \mathrm{~g}$ of 2-Chloroethylamine hydrochloride (nitrogen source) was added into the GO dispersion under sonication for 2 hours and then the mixture stirred for 12 hours under room temperature. The mixture was then transferred and sealed into $150 \mathrm{~mL}$ Teflon-lined steel autoclave in which hydrothermal reaction was carried out at $180^{\circ} \mathrm{C}$ for 12 hours. Then, the autoclave was naturally cooled to room temperature and the product was taken out. The final homogeneous mixture was placed in a quartz boat and subsequently 
transferred to a tubular furnace for carbonization. The tubular furnace was purged with nitrogen gas at room temperature for $1 \mathrm{~h}$. Then the temperature was increased at a rate of $5^{\circ} \mathrm{C} / \mathrm{min}$ up to $200^{\circ} \mathrm{C}$ for $1 \mathrm{~h}$ to remove traces of adsorbed contaminants. After that, the temperature was increased to target temperature of $500^{\circ} \mathrm{C}$ for $3 \mathrm{~h}$ under nitrogen using heating rate of $5^{\circ} \mathrm{C} / \mathrm{min}$. After the calcination process the furnace was automatically cooled to room temperature in presence of nitrogen. The obtained product was washed with distilled water thoroughly. Finally, the collected sample was dried in a vacuum oven at $70^{\circ} \mathrm{C}$ for 6 hours. The obtained nitrogen doped graphene material was subjected to detailed characterization for its textural and structural parameters (see Figure 1 and Figure 2).

\subsection{Physical Characterization}

Wide angle Powder XRD pattern of the calcined carbon materials was recorded using a Rigaku Miniflex II diffractometer with $\mathrm{Cu} \mathrm{K} \alpha$ as the radiation source at a wavelength of $0.154 \mathrm{~nm}$ with $2 \theta$ angle ranging from $10^{\circ}$ to $80^{\circ}$ with a 0.02 step

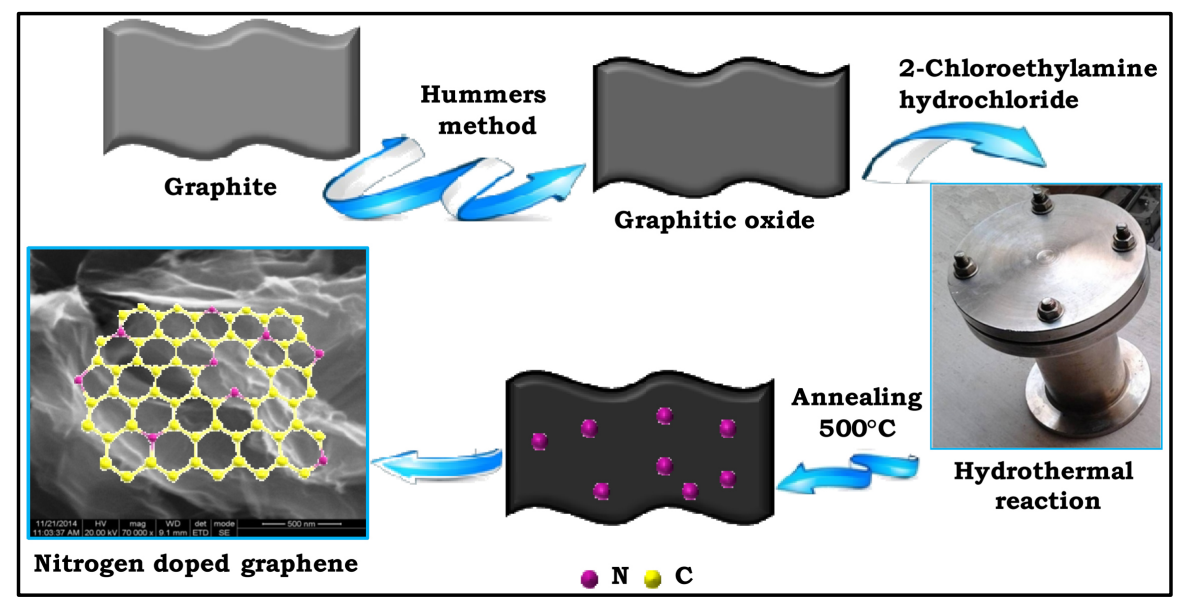

Figure 1. Schematic representation of the stepwise synthesis of nitrogen doped graphene material.

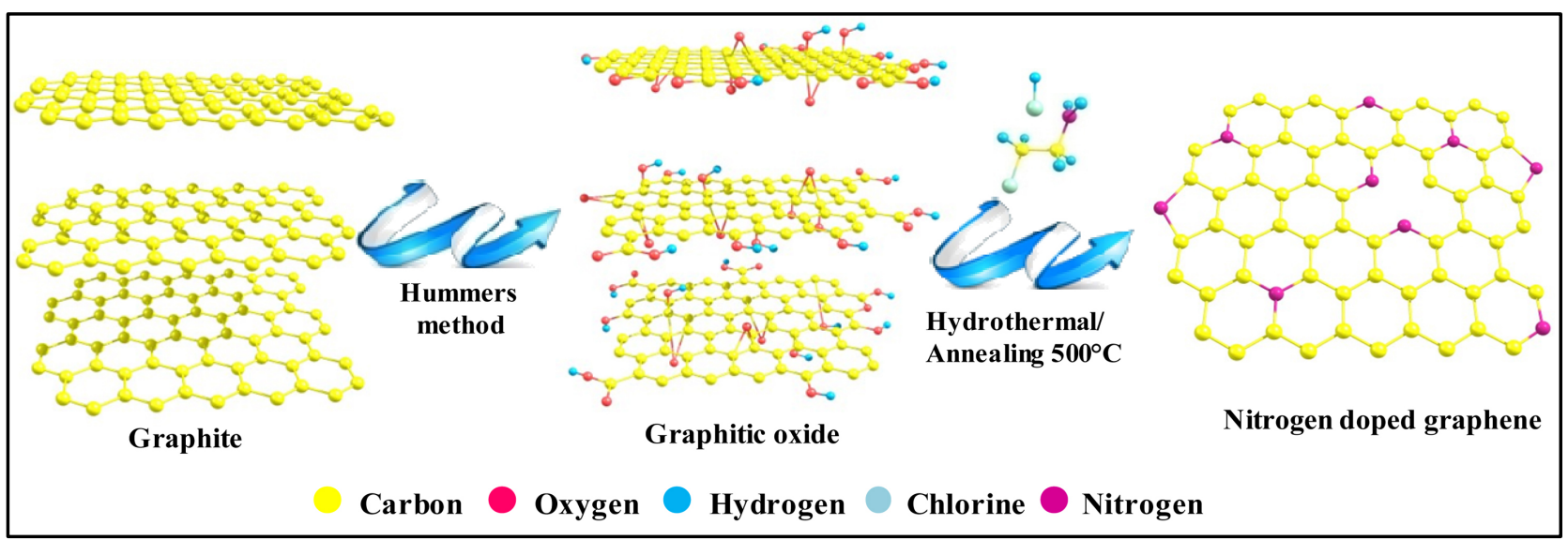

Figure 2. The graphical representation shows the conversion process from graphite to graphitic oxide and chemically derived nitrogen doped graphene. 
size. Fourier Transform Infrared Spectra (Perkin-Elmer FTIR spectrophotometer) were collected at room temperature by using the $\mathrm{KBr}$ pellet technique in the range of wave numbers $4000-400 \mathrm{~cm}^{-1}$. Raman spectroscopy and measurements were performed using HORIBA Lab RAM HR microscope. BET $\mathrm{N}_{2}$ adsorption and desorption isotherms were measured with surface area and porosity analyzer (Micromeritics Accelerated Surface Area and Porosimetry System (ASAP 2020) for the determination of surface area and total pore volume at $77 \mathrm{~K}$. Prior to the adsorption measurements, the sample was degassed at $473 \mathrm{~K}$ for $6 \mathrm{~h}$. FEI Quanta FEG 200-High Resolution Scanning Electron Microscope (HRSEM) was employed for obtaining the micrographs. JEOL JEM-2000 High Resolution Transmission Electron Microscopy (HRTEM) was employed for obtaining the micrographs. X-ray photoelectron spectroscopy (XPS) measurements were performed with an Omicron Nanotechnology spectrometer with hemispherical analyzer. The monochromatized $\mathrm{Mg} \mathrm{K} \alpha \mathrm{X}$-source $(\mathrm{E}=1253.6 \mathrm{eV})$ was operated at $15 \mathrm{kV}$ and $20 \mathrm{~mA}$. For the narrow scans, the analyzer pass energy of $25 \mathrm{eV}$ was applied. The base pressure in the analysis chamber is $5 \times 10^{-10}$ Torr. The hydrogen adsorption isotherms were carried out on high pressure volumetric analyzer (HPVA-100) from micromeritics particulate systems. The HPVA product operating pressure ranges from high vacuum to 100 bar. The span of the sample temperature during analysis can be from cryogenic to $500^{\circ} \mathrm{C}$. Sample analysis data collection is fully automated to assure quality data and high reproducibility.

\subsection{Hydrogen Adsorption/Desorption Isotherm}

High Pressure Volumetric hydrogen adsorption measurements have been carried out using High pressure volumetric analyzer (HPVA 100). The high pressure adsorption analyzer consists of a cylindrical sample cell of known volume (2cc and 10cc). All possible care for the possible sources of leak was carefully taken and long blank run tests were carried out. Care has been taken to avoid the errors due to factors such as temperature instability, leaks and additional pressure and temperature effects caused by expanding the hydrogen to the sample cell. The measurements were carried out by utilizing the systematic procedure as follows: Typically the mass of the carbon samples used for hydrogen sorption measurements is in the range of $500 \mathrm{mg}-1 \mathrm{~g}$. Earlier to measurement, the samples are degassed and heated at $200^{\circ} \mathrm{C}$ for approximately $8 \mathrm{~h}$ in vacuum. The whole system has been pressurized at the desired value by hydrogen and change in pressure was monitored. All the hydrogen adsorption measurements have been carried out at room temperature. The experiments have been repeated under the same conditions for reproducibility.

\section{Results and Discussions}

\subsection{X-Ray Diffraction Patterns}

The X-ray diffraction patterns obtained for the synthesized nitrogen doped graphene material, Graphitic Oxide (GO) and Graphite are shown in Figure 3. The prepared material shows two broad peaks around $25.1^{\circ}$ and $43.5^{\circ}$ for nitrogen 


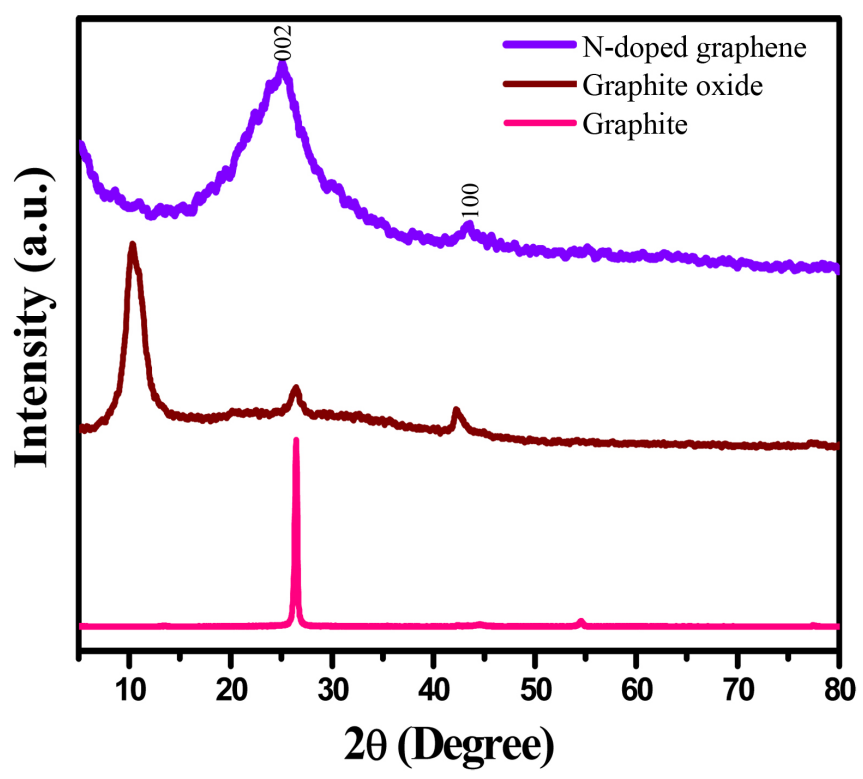

Figure 3. X-ray diffraction patterns of the nitrogen doped graphene, Graphitic Oxide and Graphite powder.

doped graphene and 26.4 and 42.3 for GO these correspond to 002 and 100 planes respectively. The (002) reflections, corresponding to coherent and parallel stacking of graphene like-sheets, become broader, signifying the increase of amorphous nature which agrees with the results of HRTEM measurements. However the (100) reflection corresponds to the honeycomb structure which is formed by sp ${ }^{2}$ hybridized carbons [57]. Generally, the heteroatom (N) doping in graphene induces defect sites and destruction in the carbon lattice, these results in low crystallinity. Furthermore, Addition of heteroatom (N) in GO, causes small changes in $2 \theta$ values.

\subsection{FT-IR Spectra Analysis}

FT-IR spectrum of the nitrogen doped graphene material is shown in Figure 4. The spectrum exhibits six bands at 3448, 2919 1642, 1462, 1382 and $1087 \mathrm{~cm}^{-1}$, respectively. FT-IR spectrum of the nitrogen doped graphene shows some characteristic bands of surface oxidized groups at $3448 \mathrm{~cm}^{-1}$. Partial removal of oxygen functional groups during thermal treatment at $180^{\circ} \mathrm{C}$ is noticed. The bands at 2919 and $2850 \mathrm{~cm}^{-1}$ were designated as the $\mathrm{C}-\mathrm{H}$ stretching vibration of the $\mathrm{CH}_{2}$ groups [36] [58]. The $\mathrm{C}=\mathrm{N}$ and $\mathrm{C}=\mathrm{C}$ stretching vibration peaks of the quinonoid and benzenoid units are located at 1642 and $1543 \mathrm{~cm}^{-1}$ while the $\mathrm{C}-\mathrm{N}$ stretching and $\mathrm{N}-\mathrm{H}$ stretching presents at 1382 and $1462 \mathrm{~cm}^{-1}$ respectively [59] [60] [61]. Because of the overlapping of peaks for $\mathrm{C}=\mathrm{C}$ and $\mathrm{C}=\mathrm{N}$, and the relative low ratio of nitrogen to carbon atom. The oxygen functionalities found for the carbonyl oxygen of quinone peaks. Peaks at 1087, assigned the existence of substituted benzene ring C-O stretching vibration of graphene sheets [62] [63]. The above observation indicated that the nitrogen doped graphene material was synthesized on the surface of the honeycomb rings of graphene. 


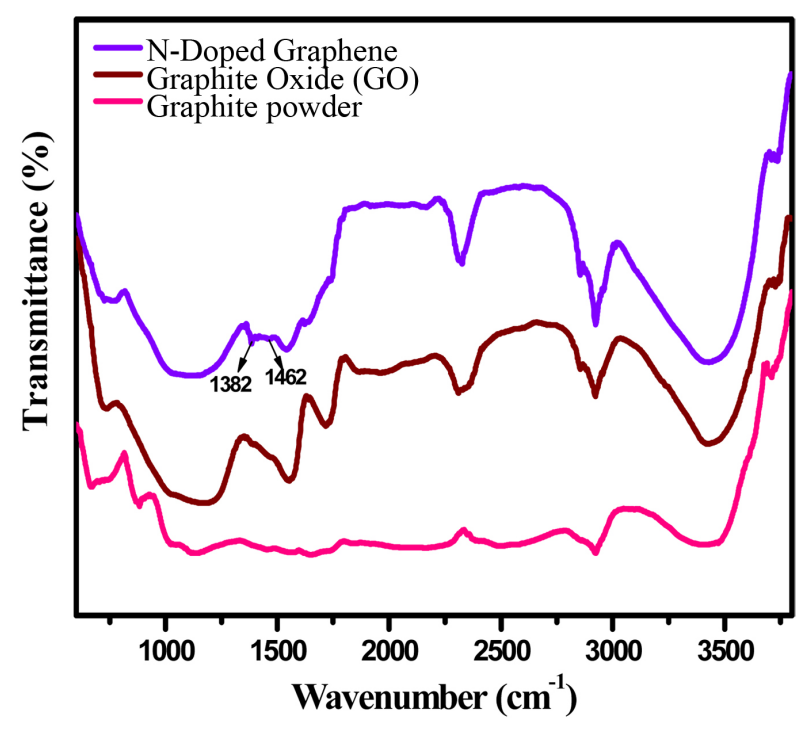

Figure 4. FT-IR spectroscopy of the nitrogen doped graphene, Graphitic Oxide and Graphite powder.

\subsection{Raman Spectroscopy}

Raman spectrum of the nitrogen doped graphene, Graphitic Oxide and Graphite powder is shown in Figure 5. Raman spectroscopy is a valuable characterization method for investigating graphene materials. Two bands were observed at 1338 and at $1592 \mathrm{~cm}^{-1}$, corresponding to the disorder-induced D band and crystalline graphitic G band, respectively [64] [65]. These bands can confirm the characteristic of graphitic carbon nanostructured materials; it is further confirmed with the XRD and HRTEM analysis. These bands can be considered as G-band and $\mathrm{D}$-band of the carbon material, breakage of carbon rings activated by several defects incorporated by incorporation of nitrogen atoms. The intensity ratio $\left(\mathrm{I}_{\mathrm{D}} / \mathrm{I}_{\mathrm{G}}\right)$ of nitrogen doped graphene $\left(\mathrm{I}_{\mathrm{D}} / \mathrm{I}_{\mathrm{G}}=1.32\right)$ is higher than Graphitic Oxide $\left(\mathrm{I}_{\mathrm{D}} / \mathrm{I}_{\mathrm{G}}=\right.$ 0.94), representing the development of defects and disordered carbon during the calcination process. Nitrogen doping tends to decrease the size of graphene structural units and introduce higher disorder in the structure of graphene. When nitrogen atoms were doped into the graphene sheets, the substitution of nitrogen atoms is accompanied by the introduction of defects such as bonding disorders and vacancies in the graphene lattice, and consequently these defects would raise the intensity of D-band of nitrogen doped graphene [66].

\subsection{BET-N 2 Adsorption/Desorption Isotherm}

The Brunauer-Emmett-Teller (BET) and adsorption/desorption isotherms were conducted to measure the specific surface area and the Barret-Joyner-Halenda $(\mathrm{BJH})$ method was utilized to measure the porous texture of these nitrogen doped graphene, Graphitic Oxide and Graphite powder and the results are shown in Figure 6. The $\mathrm{N}_{2}$ adsorption/desorption isotherms of the nitrogen doped graphene material (see Figure 6(a)) is of the type IV isotherm as per the classification of the International Union of Pure and Applied Chemistry (IUPAC) 


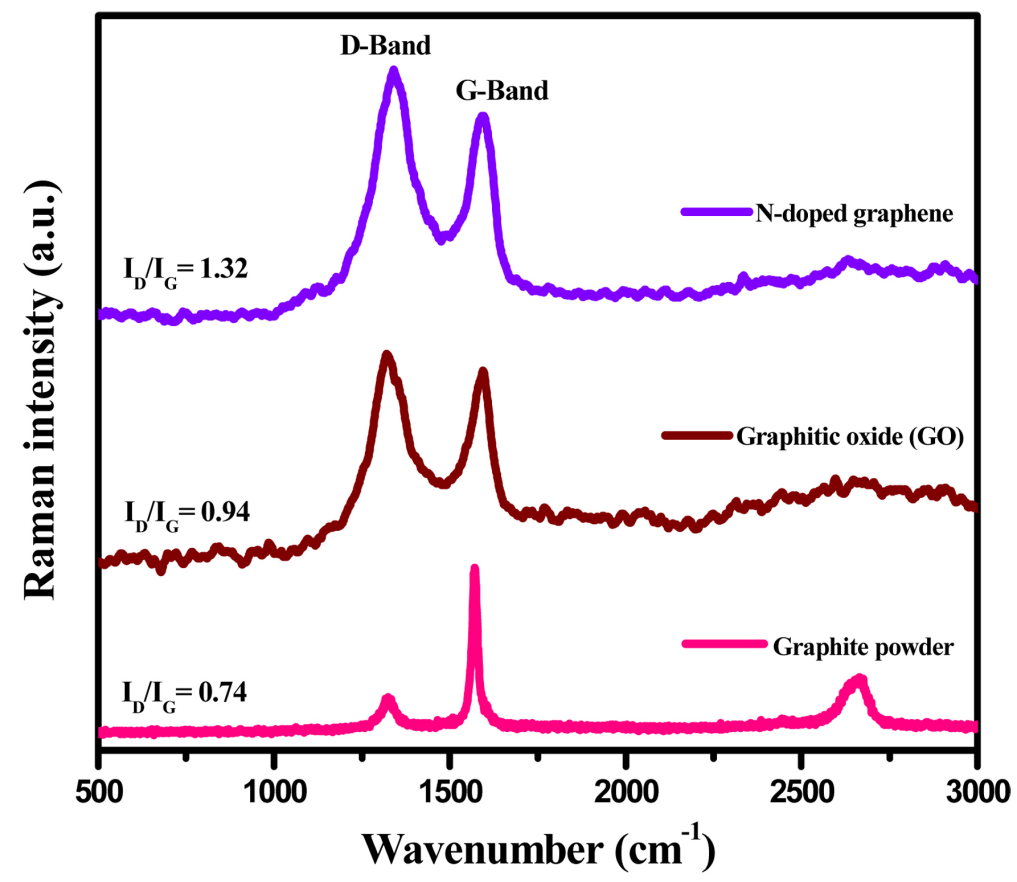

Figure 5. Raman spectrum of the nitrogen doped graphene, Graphitic Oxide and Graphite powder.

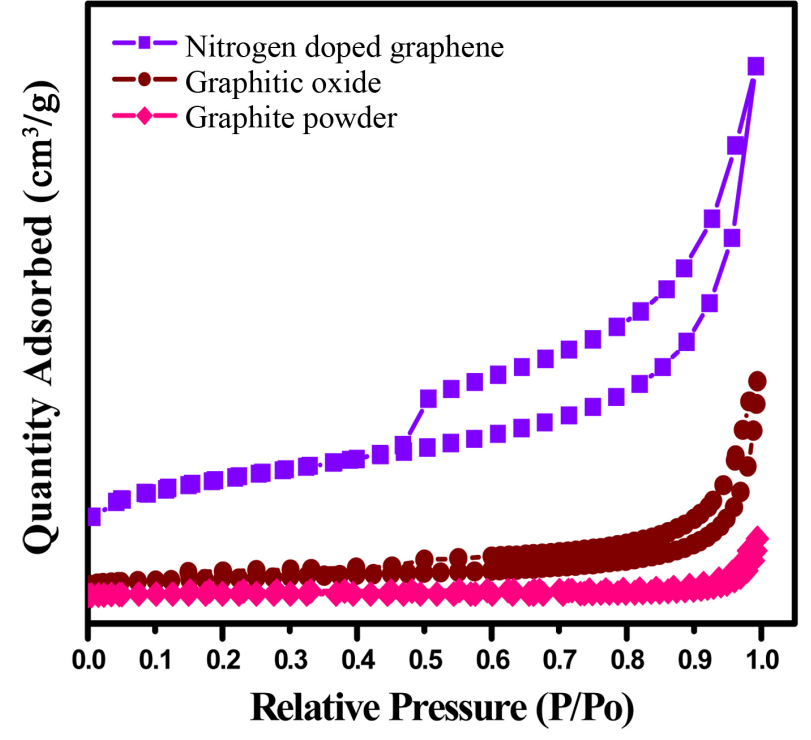

(a)

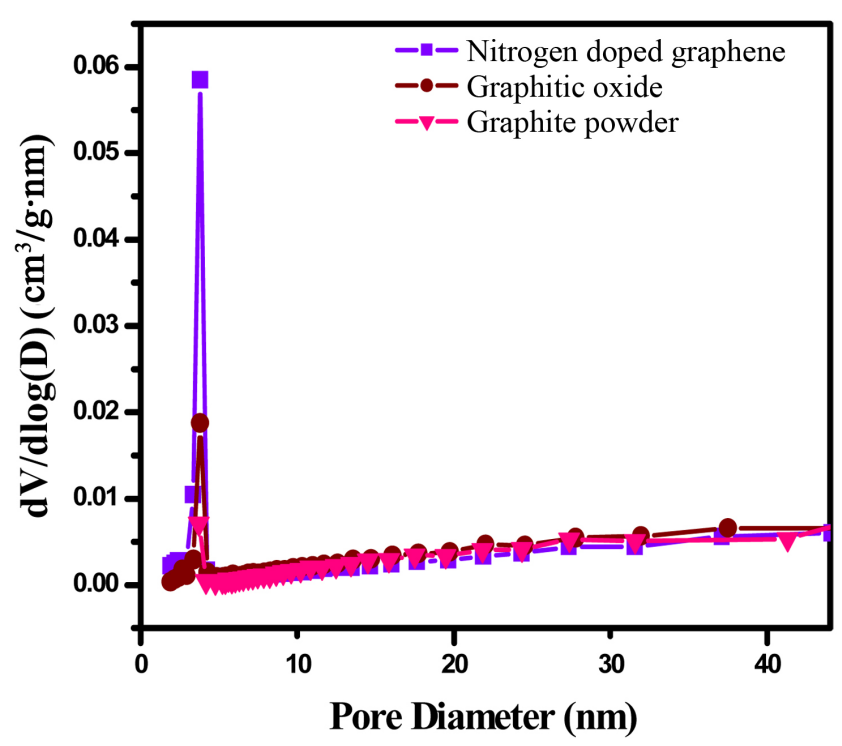

(b)

Figure 6. (a) BET- $\mathrm{N}_{2}$ adsorption/desorption isotherm and (b) Poresize distribution of the nitrogen doped graphene, and also Graphitic Oxide and Graphite powder.

[67]. Herein nitrogen doped graphene shows a vertical uptake under $\mathrm{P} / \mathrm{P}_{0}=0.04$, and a hysteresis loop from $\mathrm{P} / \mathrm{P}_{0}=0.5$ to $\mathrm{P} / \mathrm{P}_{0}=1.0$ which is due to the co-existence of both micropores and mesopores. It can be seen that there are little ultramicropores in the nitrogen doped graphene material [68]. It is believed that the porous materials with a surface area would provide more active sites and thus improve the hydrogen storage capacity [69]. The pore size distribution 
curves shown in Figure 6(b), estimated according to the Barrett-Joyner-Halenda (BJH) model, confirm the greater part of the pores in the synthesized graphene materials have size below $5 \mathrm{~nm}$. The doping of heteroatom $(\mathrm{N})$ into graphene is making the changes of surface area and pore size of the prepared material. Furthermore, the graphitic Oxide (GO) possesses a BET surface area $\left(78 \mathrm{~m}^{2} / \mathrm{g}\right)$ smaller than that of the nitrogen doped graphene material $\left(580 \mathrm{~m}^{2} / \mathrm{g}\right)$. Therefore, it can be stated that after the incorporation of nitrogen on the graphene material, would increase the surface area of this material. Nevertheless, heteroatom $(\mathrm{N})$ doped graphene is shown the prerequisite of high specific surface area makes heteroatom $(\mathrm{N})$ doped graphene readily aligned in a layered framework [70] [71]. The values of surface area, total pore volume, micropore volume, are summarized (see Table 1).

\subsection{High Resolution Scanning Electron Microscopy (HRSEM)}

The High Resolution Scanning Electron micrograph (HRSEM) of the nitrogen doped graphene material is shown in Figure 7. The morphological aspects of the graphene shows transparent, thin graphene sheets with wrinkled (see Figure $7(\mathrm{a})$ and Figure $7(\mathrm{~b})$ ), crumbled (see Figure $7(\mathrm{c})$ ) and folded are effectively seen in the synthesized graphene material for different magnifications, the graphene sheet can self-arrange into a structure, comprising of a head embeddings into a paper like graphene sheet (see Figure $7(b)$ and Figure $7(c)$ ). The waves like morphology in graphene may begin from the heteroatoms or defects stayed in the plane of graphene, and the dispersing focal point of waves should contain heteroatoms or defects [72]. However, crumpled graphene sheets randomly aggregated and connected with each other. These crumpled nitrogen containing graphene sheets were able to prevent restacking between layers when they were utilized as adsorbents [73]. The essential graphene smooth flake surface was to a certain extent exposed, while it is positioned that the rough division was functionalized with heteroatom (nitrogen) containing graphene structure. For comparison HRSEM images of the Graphitic oxide (GO) are shown in Figure 7(d) and Figure $7(\mathrm{e})$ for different magnifications. To investigate the percentage of element, the SEM-EDAX investigation was carried out for this material. The

Table 1. BET- $\mathrm{N}_{2}$ adsorption/desorption isotherm results and also the hydrogen adsorption/desorption results are summarized.

\begin{tabular}{ccccccc}
\hline S. No & $\begin{array}{c}\text { Samples } \\
\text { name }\end{array}$ & $\begin{array}{c}\text { Surface area } \\
\left(\mathrm{m}^{2} / \mathrm{g}\right)\end{array}$ & $\begin{array}{c}\text { Micropore } \\
\text { Area }\left(\mathrm{m}^{2} / \mathrm{g}\right)\end{array}$ & $\begin{array}{c}\text { Total pore } \\
\text { Volume } \\
\left(\mathrm{cm}^{3} / \mathrm{g}\right)\end{array}$ & $\begin{array}{c}\text { Micropore } \\
\text { volume } \\
\left(\mathrm{cm}^{3} / \mathrm{g}\right)\end{array}$ & $\begin{array}{c}\mathrm{H}_{2} \text { adsorption } \\
\text { capaty at } 298 \mathrm{~K} \\
\text { and } 90 \mathrm{bar} \\
(\mathrm{wt} \%)\end{array}$ \\
\hline 1 & $\begin{array}{c}\text { N-Doped } \\
\text { graphene }\end{array}$ & 580 & 396 & 0.416 & 0.192 & 1.5 \\
\hline & $\begin{array}{c}\text { Graphitic } \\
\text { Oxide (GO) }\end{array}$ & 78 & 10.8 & 0.119 & 0.004 & 0.21 \\
\hline & $\begin{array}{c}\text { Graphite } \\
\text { Powder }\end{array}$ & 0.65 & 1.55 & 0.012 & 0.008 & 0.14 \\
\hline
\end{tabular}



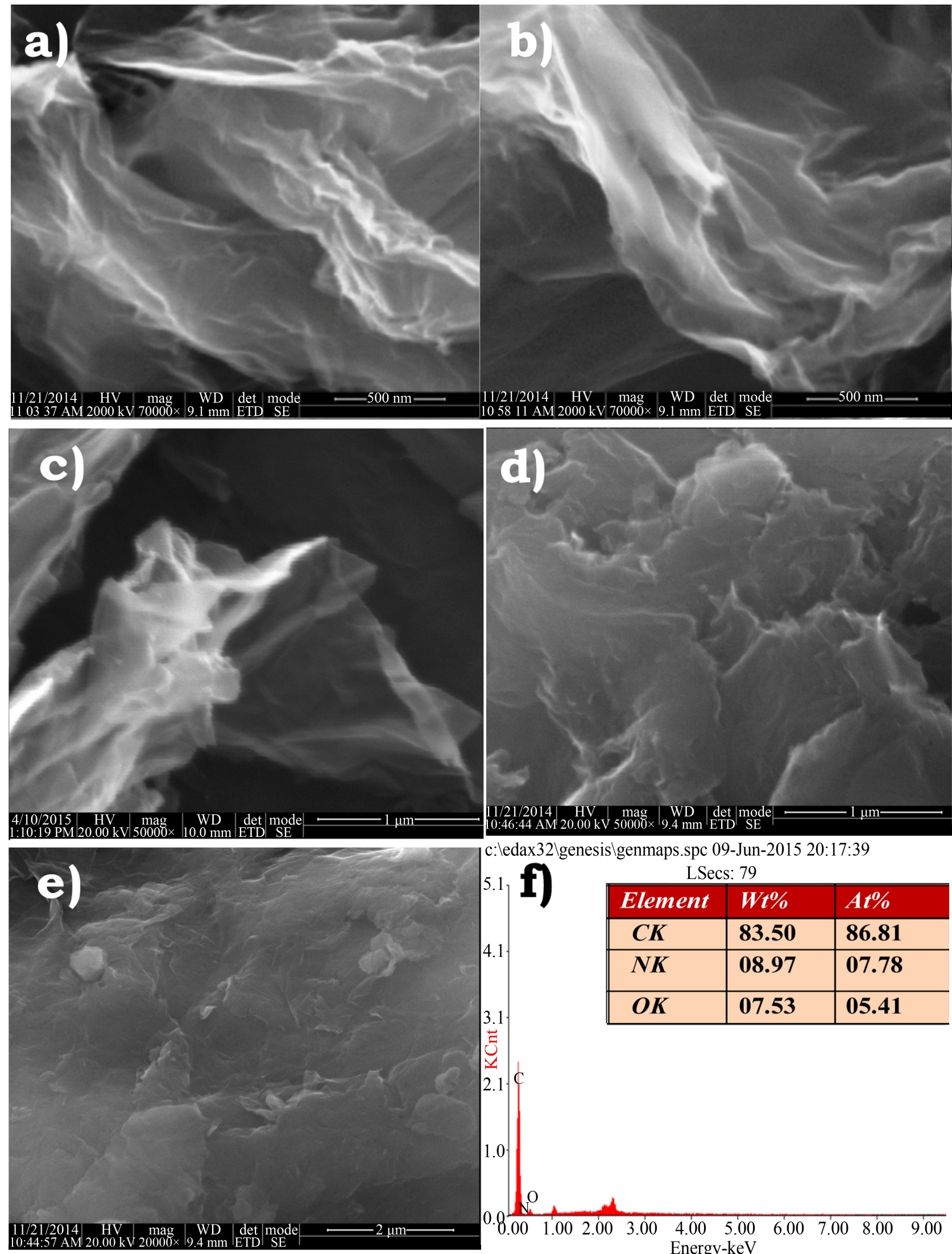

c:ledax32\genesis \genmaps.spc 09-Jun-2015 20:17:39

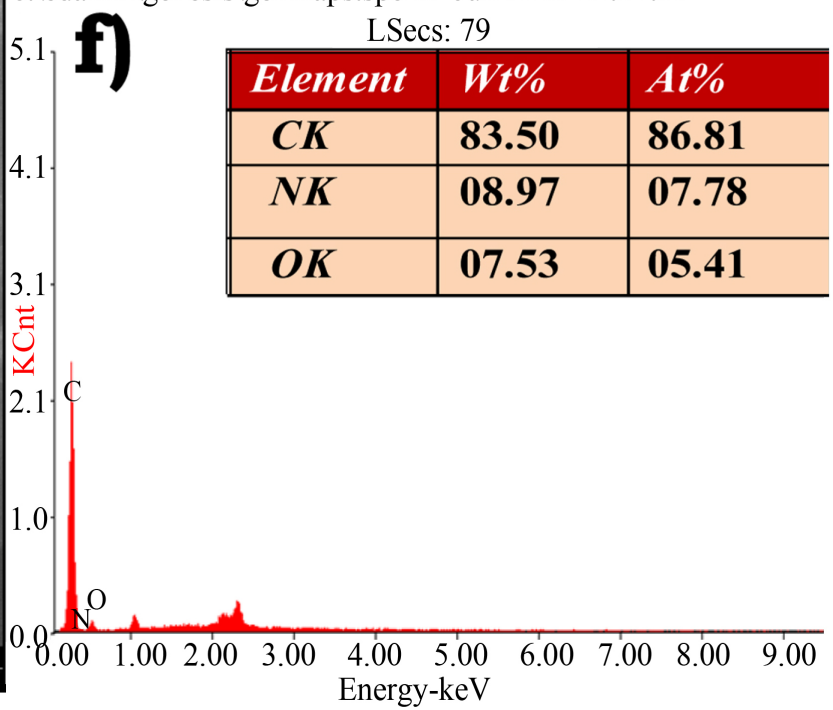

Figure 7. (a), (b), (c) and (d) High resolution scanning electron microscopy (HRSEM) images of the nitrogen doped graphene material for different magnifications. 
amount of nitrogen observed in the carbon matrix was $\sim 7.5$ at \% (see Figure $7(f)$ ). This value is higher than those of most doped graphene materials. Moreover, the emergence of this behavior of surface morphology is responsible for the improvement in hydrogen adsorption properties.

\subsection{High Resolution Transmission Electron Microscopy (HRTEM)}

The high resolution transmission electron micrograph (HRTEM) of the nitrogen doped graphene is shown in Figures 8(a)-(d). A high resolution TEM image Figures $8(a)-(c)$ shows crumpled and wavy sheets like images observed. Figure 8(d) shows that the porous graphene sheet is shows amorphous in nature. This observation is in agreement with the observation of HRSEM images (see Figure 7). The selected area diffraction pattern (SAED) of the nitrogen doped graphene material shows two diffraction rings belonging to (002) and (100) planes respectively (see Figure 8(d) inset figure) and also some diffraction spots for each order of diffraction. These spots compose ordinary hexagons with unusual rotational angles [73]. It indicates the essentially random overlapping of the graphene sheets. This result is in conformity with the observation of XRD patterns (see Figure 2). However this TEM characterization confirmed the existence of an amorphous surface and less crystalline disorder of this prepared nitrogen doped graphene material. Simultaneously scanning TEM (STEM) with elemental mapping has been carried out to confirm the nitrogen substitution in the carbon lattice and to characterize the uniformity of substitution (see Figures 9(e)-(h)).

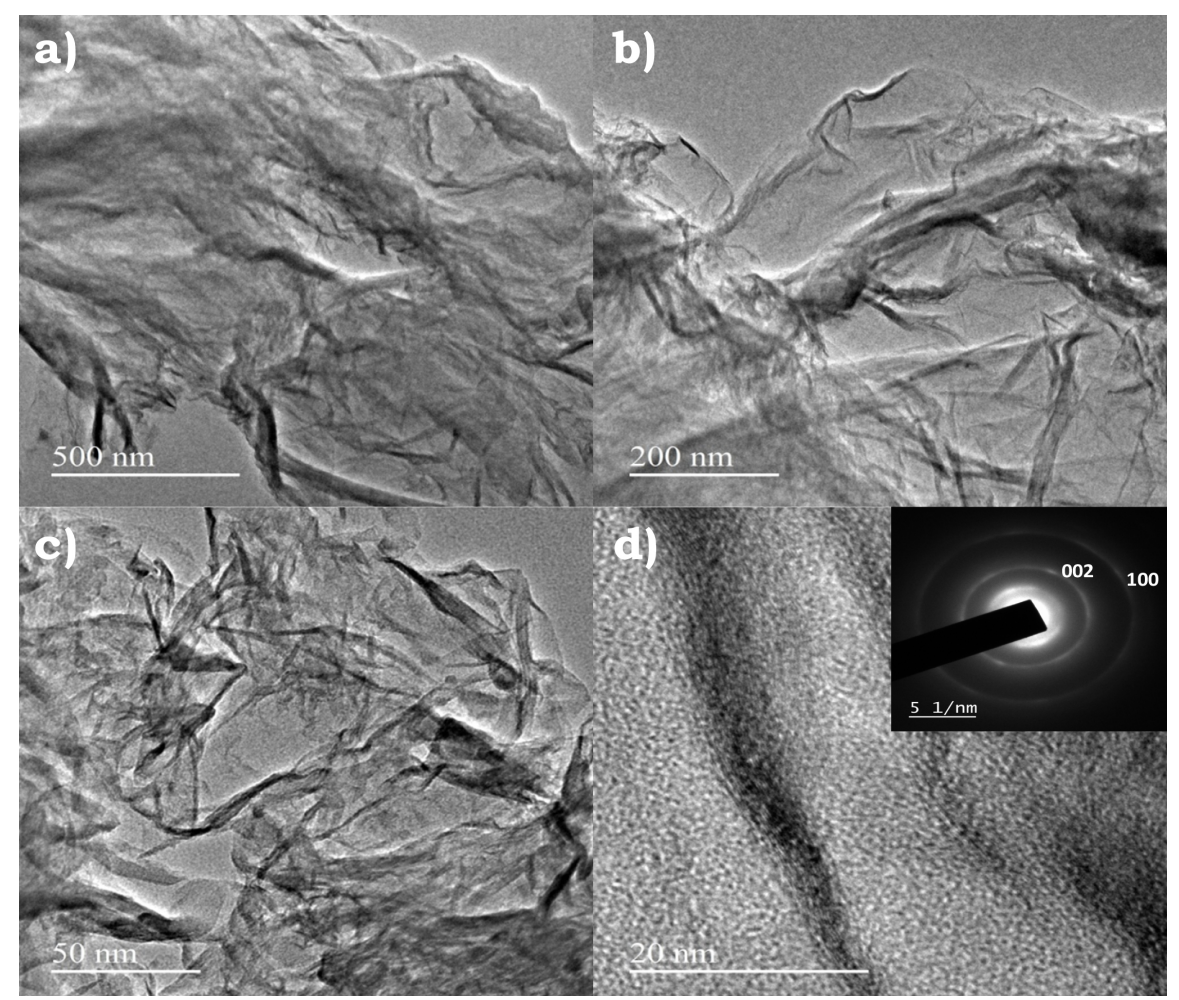

Figure 8. (a), (b), (c) and (d) High resolution transmission electron microscopy (HRTEM) images for different magnifications and (d-inset figure) SAED patterns of the nitrogen doped graphene material. 
These results confirm the carbon (Red) nitrogen (yellow) and oxygen (blue) atoms have been uniformly distributed in the framework. However, the elemental percentage of the prepared material was investigated by TEM-EDAX analysis. The total percentage of nitrogen observed in the carbon matrix was $\sim 7.5$ at\% (see Figure 9(i) and Figure 9(j)).

\subsection{X-Ray Photoelectron Spectroscopy (XPS)}

XPS analysis was carried out to determine the exact amount of functional component and is shown in Figure 10. The XPS-survey scan of the graphene material show three peaks corresponding to Carbon (C1s), Nitrogen (N1s) and Oxygen (O1s) respectively (see Figure 10(a)). C1s scans show an intense peak at around $284.6 \mathrm{eV}$ assigned to $\mathrm{sp}^{2}$-hybridized carbon and carbon atoms single or double bonded to nitrogen or oxygen, respectively [74] [75]. The C1s peak can be deconvoluted into three different components positioned at about 284.1, 285.3 and $288.1 \mathrm{eV}$, which can be ascribed to $\mathrm{C}-\mathrm{C} / \mathrm{C}=\mathrm{C}, \mathrm{C}-\mathrm{O} / \mathrm{C}=\mathrm{O}$, and $\mathrm{C}-\mathrm{N} / \mathrm{O}-\mathrm{C}=\mathrm{O}$ bonding, respectively (see Figure 10(b)). The main peak at $284.6 \mathrm{eV}$ is associated to the graphitic carbon. This means that the majority of the carbon atoms are arranged in conjugated honeycomb lattices [76] [77] [78] [79]. Accordingly, the carbon 1s spectrum reveals $\mathrm{N}$-functionalized carbon in which the nitrogen atoms are anchored within carbon with a graphitic microstructure. The highresolution N1s spectra of the nitrogen doped graphene material can also be deconvoluted into three component peaks, namely pyrrolic nitrogen $(399.1 \mathrm{eV})$,

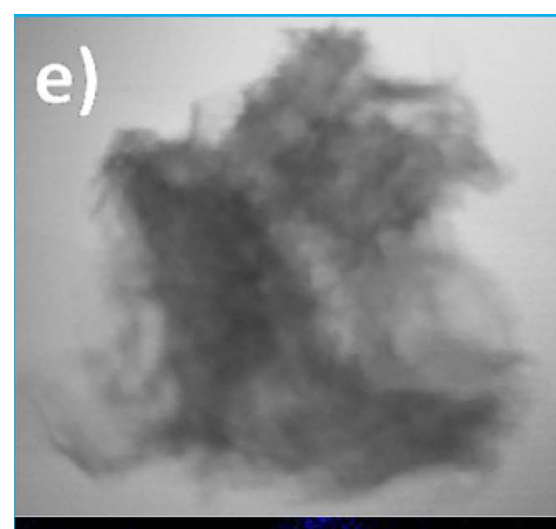

\section{h)

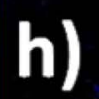

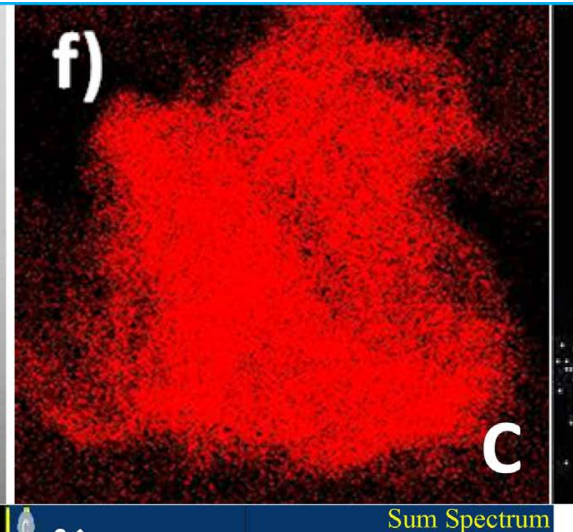
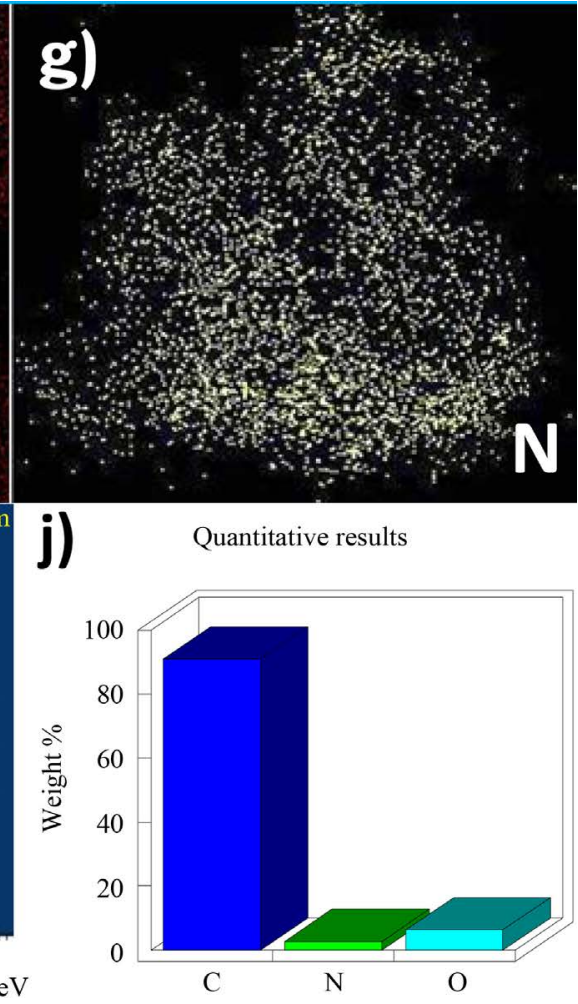

Figure 9. (e) STEM image (f) (g) and (h) Elemental mapping of C, N, O and (i), (j) HRTEM-EDAX analysis images of the nitrogen doped graphene material. 


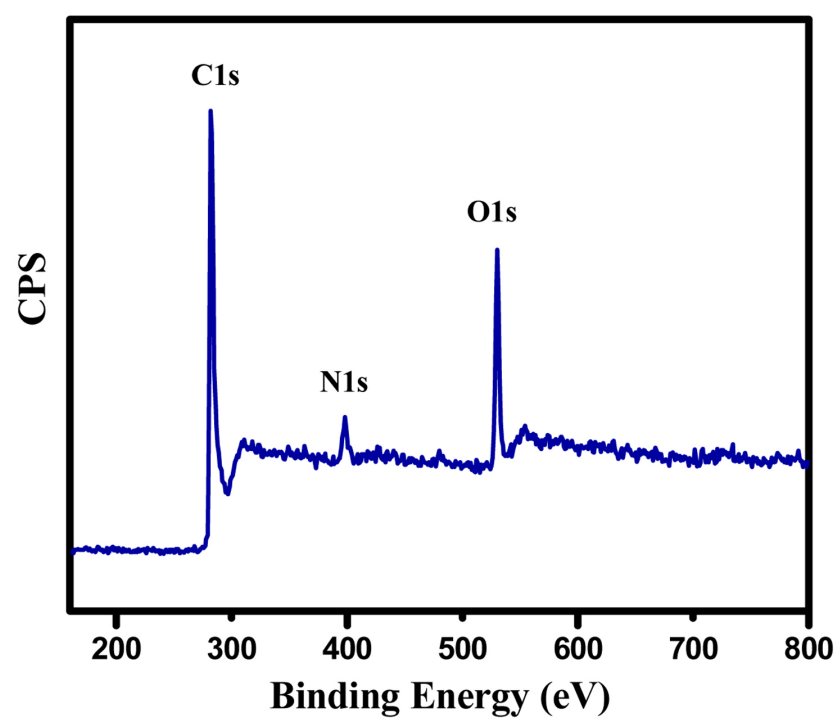

(a)

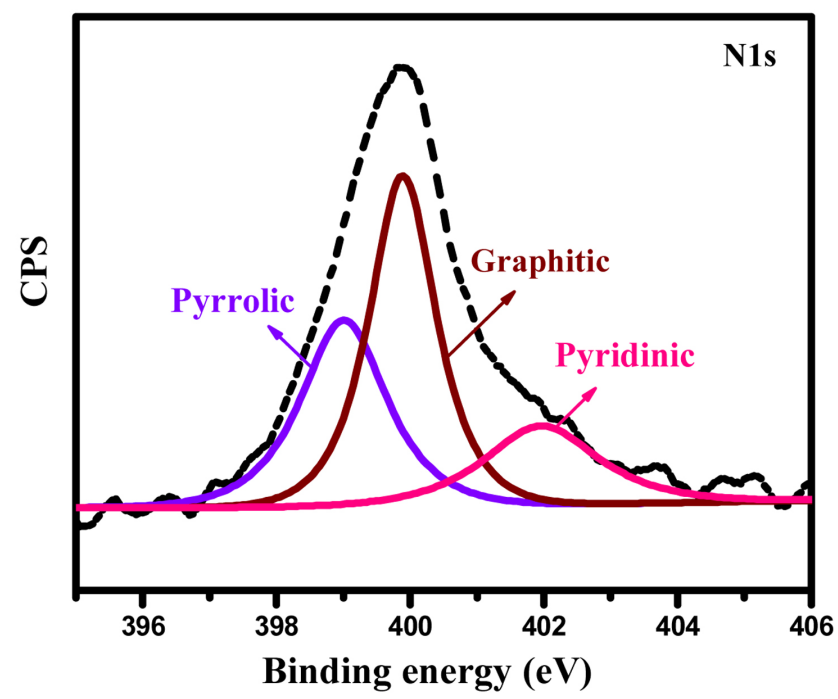

(c)

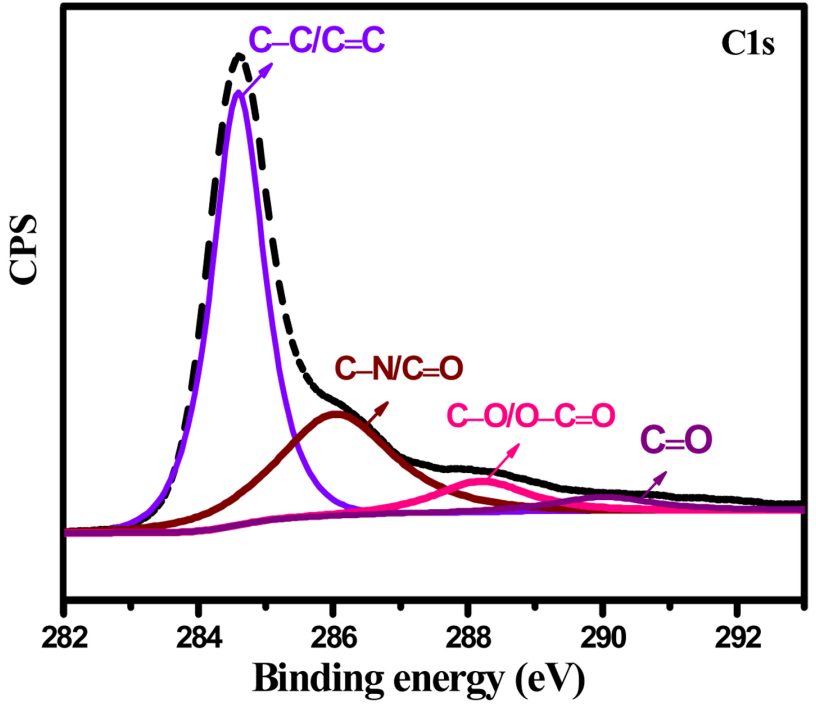

(b)

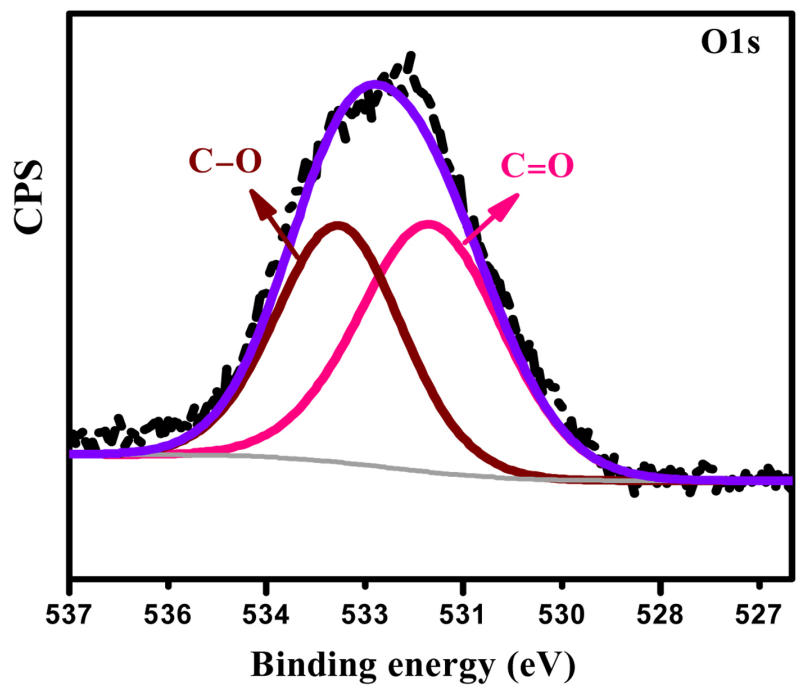

(d)

Figure 10. X-ray Photoelectron Spectroscopy (XPS) images of the nitrogen doped graphene material.

graphitic nitrogen $(399.8 \mathrm{eV})$ and pyridinic nitrogen $(401.8 \mathrm{eV})$, respectively [80]. These results indicate that most of the nitrogen was embedded in the graphitic structure in the form of pyrrolic- $\mathrm{N}$, pyridinic- $\mathrm{N}$ and graphitic- $\mathrm{N}$ in the nitrogen doped graphitic layer (see Figure 10(c)). The O1s peaks are broad after that doping of nitrogen signifying the existence of different chemical states of oxygen. Generally oxygen arises from the thermally constant groups in the carbon with the exception of that of oxygen or water absorbed on the graphene surface. The existence of the oxygen is a characteristic phenomenon as the surface of graphene tends to be oxidized somewhat when handled at ambient conditions. The oxygen functionalities found for the main O1s peak (See Figure 10(d)) are carbonyl oxygen of quinone $(532.5 \mathrm{eV})$, after deconvolution of two peaks attributed to non-carbonyl oxygen atoms in esters $(533.0 \mathrm{eV})$, and oxygen atoms in carboxylic groups $(531.8 \mathrm{eV})$ respectively [81]. These abundant oxygen and nitrogen functional groups on the sur- 
face of graphene materials combined with specific surface area and micropores offer a strong tendency to distribute exciting adsorption sites [36]. The high nitrogen content in the carbon materials is advantageous to the arrangement of defects and the improvement of adsorption properties, which are able to enhance the hydrogen storage capacity of this nitrogen-doped graphene material.

\subsection{The Hydrogen Adsorption/Desorption Isotherm}

The hydrogen adsorption/desorption isotherm of the nitrogen doped graphene, Graphitic Oxide and Graphite powder is shown in Figure 11. The hydrogen adsorption isotherm has been carried out $298 \mathrm{~K}$ and 90 bar pressure. The nitrogen doped graphene material showed nearly $\sim 1.5 \mathrm{wt} \%$ hydrogen storage capacity at room temperature and 90 bar pressure. In this extent the graphitic oxide (GO) showed $\sim 0.21 \mathrm{wt} \%$ hydrogen storage capacity at room temperature and 90 bar. This value is lesser than that of nitrogen doped graphene material. However nitrogen doping of graphene materials takes up substitution positions in the carbon lattice, there is transportation of hydrogen atoms on to the graphene surface. Furthermore, these results reveal that the nitrogen doping on graphene materials can extensively modify the catalytic effect of the graphene materials for hydrogen dissociative adsorption, foremost for the improvement of the dissociative hydrogen adsorption [82]. This observation suggests that the nitrogen atoms take part in a role in the hydrogen adsorption capacity at room temperature. A previous study recommended that the presence of nitrogen atoms in graphene sheets increases the enthalpy of hydrogen adsorption [48] [49]. Potentially almost all the adsorbed amount can be desorbed which is an interesting characteristic expected for hydrogen storage materials.

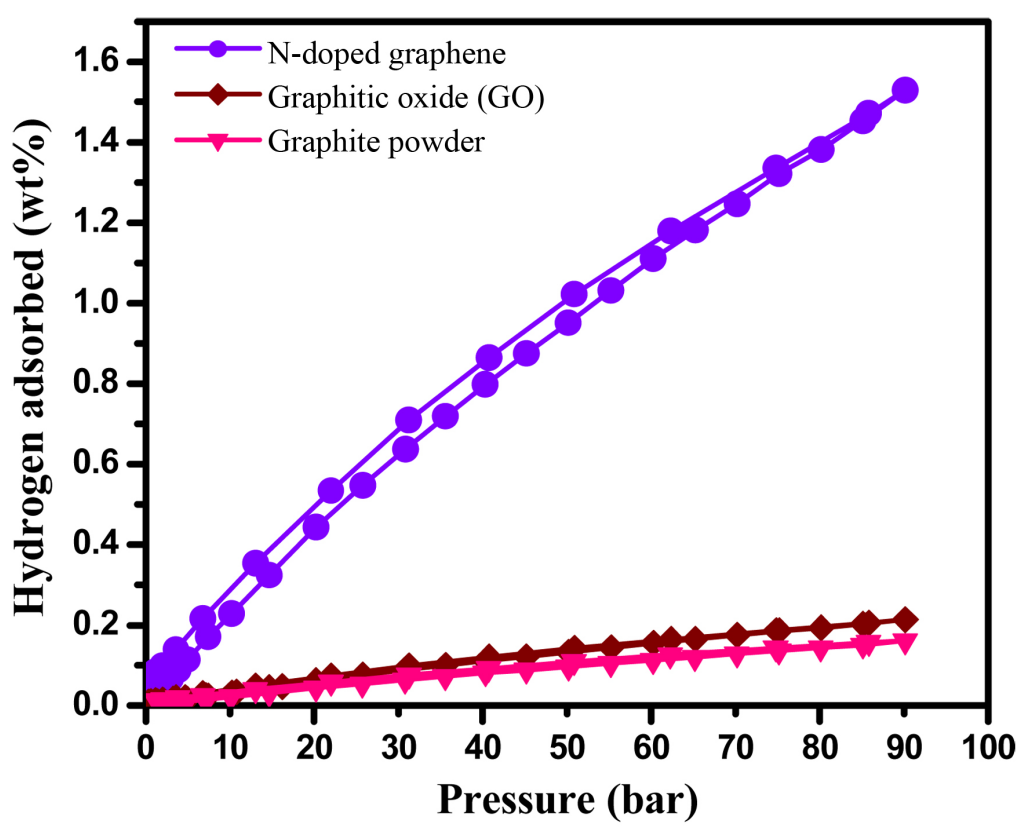

Figure 11. Hydrogen adsorption/desorption isotherm of the nitrogen doped graphene, Graphitic Oxide and Graphite powder at $298 \mathrm{~K}$ and 90 bar Pressure. 


\section{Conclusion}

An efficient, reproducible nitrogen doped graphene material utilizing 2-Chloroethylamine hydrochloride as nitrogen source has been prepared. It is established that nitrogen content in graphene layers up to $\sim 7.5$ at $\%$ can be achieved. The nitrogen doped graphene material achieved hydrogen storage capacity of $\sim 1.5 \mathrm{wt} \%$ at $298 \mathrm{~K}$ and 90 bar.

\section{Acknowledgements}

The authors wish to record their grateful thanks to the Department of Science and Technology (DST) for setting up National Centre for Catalysis Research (NCCR), Ministry New and Renewable Energy (MNRE) of the Government of India for supporting the hydrogen storage activity of this centre.

\section{References}

[1] Ströbel, R., Garche, J., Moseley, P.T., Jörissen, L. and Wolf, G. (2006) Hydrogen Storage by Carbon Materials. Journal of Power Sources, 159, 781-801.

[2] Hynek, S., Fuller, W. and Bentley, J. (1997) Hydrogen Storage by Carbon Sorption. International Journal of Hydrogen Energy, 22, 601-610.

[3] Singh, S., Jain, S., Ps, V., Tiwari, A.K., Nouni, M.R., Pandey, J.K., et al. (2015) Hydrogen: A Sustainable Fuel for Future of the Transport Sector. Renewable and Sustainable Energy Reviews, 51, 623-633.

[4] Wang, L. and Yang, R.T. (2009) Hydrogen Storage Properties of N-Doped Microporous Carbon. The Journal of Physical Chemistry C, 113, 21883-21888. https://doi.org/10.1021/jp908156v

[5] Spyrou, K., Gournis, D. and Rudolf, P. (2013) Hydrogen Storage in Graphene-Based Materials: Efforts towards Enhanced Hydrogen Absorption. ECS Journal of Solid State Science and Technology, 2, M3160-M3169. https://doi.org/10.1149/2.018310jss

[6] Niaz, S., Manzoor, T. and Pandith, A.H. (2015) Hydrogen Storage: Materials, Methods and Perspectives. Renewable and Sustainable Energy Reviews, 50, 457-469.

[7] Titirici, M.-M., White, R.J., Brun, N., Budarin, V.L., Su, D.S., del Monte, F., Clark, J.H. and MacLachlan, M.J. (2015) Sustainable Carbon Materials. Chemical Society Reviews, 44, 250-290. https://doi.org/10.1039/C4CS00232F

[8] Hurst, K.E., Parilla, P.A., O’Neill, K.J. and Gennett, T. (2016) An International Multi-Laboratory Investigation of Carbon-Based Hydrogen Sorbent Materials. Applied Physics A, 122, 1-9. https://doi.org/10.1007/s00339-015-9537-x

[9] Dillon, A.C., Jones, K.M., Bekkedahl, T.A., Kiang, C.H., Bethune, D.S. and Heben, M.J. (1997) Storage of Hydrogen in Single-Walled Carbon Nanotubes. Nature, 386, 377-379. https://doi.org/10.1038/386377a0

[10] Chambers, A., Park, C., Baker, R.T.K. and Rodriguez, N.M. (1998) Hydrogen Storage in Graphite Nanofibers. The Journal of Physical Chemistry B, 102, 4253-4256. https://doi.org/10.1021/jp9801141

[11] Bader, N. and Ouederni, A. (2016) Optimization of Biomass-Based Carbon Materials for Hydrogen Storage. Journal of Energy Storage, 5, 77-84.

[12] Zhao, J., Liu, Y., Quan, X., Chen, S., Yu, H. and Zhao, H. (2017) Nitrogen-Doped Carbon with a High Degree of Graphitization Derived from Biomass as High-Per- 
formance Electrocatalyst for Oxygen Reduction Reaction. Applied Surface Science, 396, 986-993.

[13] Sankaran, M. and Viswanathan, B. (2006) The Role of Heteroatoms in Carbon Nanotubes for Hydrogen Storage. Carbon, 44, 2816-2821.

[14] Wang, H., Maiyalagan, T. and Wang, X. (2012) Review on Recent Progress in Nitrogen-Doped Graphene: Synthesis, Characterization, and Its Potential Applications. Acs Catalysis, 2, 781-794. https://doi.org/10.1021/cs200652y

[15] Sari, F.N.I. and Ting, J.-M. (2015) One Step Microwaved-Assisted Hydrothermal Synthesis of Nitrogen Doped Graphene for High Performance of Supercapacitor. Applied Surface Science, 355, 419-428.

[16] Wang, Z., Sun, L., Xu, F., Zhou, H., Peng, X., Sun, D., Wang, J. and Du, Y. (2016) Nitrogen-Doped Porous Carbons with High Performance for Hydrogen Storage. International Journal of Hydrogen Energy, 41, 8489-8497.

[17] Avouris, P. and Dimitrakopoulos, C. (2012) Graphene: Synthesis and Applications. Materials Today, 15, 86-97.

[18] Grochala, W. and Edwards, P.P. (2004) Thermal Decomposition of the Non-Interstitial Hydrides for the Storage and Production of Hydrogen. Chemical Reviews, 104, 1283-1316. https://doi.org/10.1021/cr030691s

[19] Ci, L., Zhu, H., Wei, B., Xu, C. and Wu, D. (2003) Annealing Amorphous Carbon Nanotubes for Their Application in Hydrogen Storage. Applied Surface Science, 205, 39-43.

[20] Georgakilas, V., Perman, J.A., Tucek, J. and Zboril, R. (2015) Broad Family of Carbon Nanoallotropes: Classification, Chemistry, and Applications of Fullerenes, Carbon Dots, Nanotubes, Graphene, Nanodiamonds, and Combined Superstructures. Chemical Reviews, 115, 4744-4822.

https://doi.org/10.1021/cr500304f

[21] Tozzini, V. and Pellegrini, V. (2013) Prospects for Hydrogen Storage in Graphene. Physical Chemistry Chemical Physics, 15, 80-89. https://doi.org/10.1039/C2CP42538F

[22] Rao, C.N.R., Sood, A.K., Subrahmanyam, K.S. and Govindaraj, A. (2009) Graphene: The New Two-Dimensional Nanomaterial. Angewandte Chemie International Edition, 48, 7752-7777. https://doi.org/10.1002/anie.200901678

[23] Novoselov, K.S., Geim, A.K., Morozov, S.V., Jiang, D., Zhang, Y., Dubonos, S.V., Grigorieva, I.V. and Firsov, A.A. (2004) Electric Field Effect in Atomically Thin Carbon Films. Science, 306, 666-669. https://doi.org/10.1126/science.1102896

[24] Geim, A.K. and Novoselov, K.S. (2007) The Rise of Graphene. Nature Materials, 6, 183-191. https://doi.org/10.1038/nmat1849

[25] Castro Neto, A.H., Guinea, F., Peres, N.M.R., Novoselov, K.S. and Geim, A.K. (2009) The Electronic Properties of Graphene. Reviews of Modern Physics, 81, 109 162. https://doi.org/10.1103/RevModPhys.81.109

[26] Cheng, M., Yang, R., Zhang, L., Shi, Z., Yang, W., Wang, D., Xie, G., Shi, D. and Zhang, G. (2012) Restoration of Graphene from Graphene Oxide by Defect Repair. Carbon, 50, 2581-2587.

[27] Gadipelli, S. and Guo, Z.X. (2015) Graphene-Based Materials: Synthesis and Gas Sorption, Storage and Separation. Progress in Materials Science, 69, 1-60.

[28] Lee, S.M. and Lee, Y.H. (2000) Hydrogen Storage in Single-Walled Carbon Nanotubes. Applied Physics Letters, 76, 2877-2879.

https://doi.org/10.1063/1.126503 
[29] Ansón, A., Lafuente, E., Urriolabeitia, E., Navarro, R., Benito, A.M., Maser, W.K. and Martínez, M.T. (2006) Hydrogen Capacity of Palladium-Loaded Carbon Materials. The Journal of Physical Chemistry B, 110, 6643-6648. https://doi.org/10.1021/jp057206c

[30] Froudakis, G.E. (2001) Hydrogen Interaction with Single-Walled Carbon Nanotubes: A Combined Quantum-Mechanics/Molecular-Mechanics Study. Nano Letters, 1, 179-182. https://doi.org/10.1021/nl015504p

[31] Allen, M.J., Tung, V.C. and Kaner, R.B. (2010) Honeycomb Carbon: A Review of Graphene. Chemical Reviews, 110, 132-145. https://doi.org/10.1021/cr900070d

[32] Wang, H., Zhou, Y., Wu, D., Liao, L., Zhao, S., Peng, H. and Liu, Z. (2013) Synthesis of Boron-Doped Graphene Monolayers Using the Sole Solid Feedstock by Chemical Vapor Deposition. Small, 9, 1316-1320. https://doi.org/10.1002/smll.201203021

[33] Li, R., Wei, Z., Gou, X. and Xu, W. (2013) Phosphorus-Doped Graphene Nanosheets as Efficient Metal-Free Oxygen Reduction Electrocatalysts. RSC Advances, 3, 9978-9984. https://doi.org/10.1039/c3ra41079j

[34] Yang, Z., Yao, Z., Li, G., Fang, G., Nie, H., Liu, Z., Zhou, X., Chen, X.A. and Huang, S. (2012) Sulfur-Doped Graphene as an Efficient Metal-Free Cathode Catalyst for Oxygen Reduction. ACS Nano, 6, 205-211. https://doi.org/10.1021/nn203393d

[35] Lin, Z., Song, M.-K., Ding, Y., Liu, Y., Liu, M. and Wong, C.-P. (2012) Facile Preparation of Nitrogen-Doped Graphene as a Metal-Free Catalyst for Oxygen Reduction Reaction. Physical Chemistry Chemical Physics, 14, 3381-3387. https://doi.org/10.1039/c2cp00032f

[36] Albero, J. and Garcia, H. (2015) Doped Graphenes in Catalysis. Journal of Molecular Catalysis A: Chemical, 408, 296-309.

[37] Wang, X., Li, X., Zhang, L., Yoon, Y., Weber, P.K., Wang, H., Guo, J. and Dai, H. (2009) N-Doping of Graphene through Electrothermal Reactions with Ammonia. Science, 324, 768-771. https://doi.org/10.1126/science.1170335

[38] Sankaran, M., Viswanathan, B. and Srinivasa Murthy, S. (2008) Boron Substituted Carbon Nanotubes-How Appropriate Are They for Hydrogen Storage? International Journal of Hydrogen Energy, 33, 393-403.

[39] Ariharan, A., Viswanathan, B. and Nandhakumar, V. (2016) Hydrogen Storage on Boron Substituted Carbon Materials. International Journal of Hydrogen Energy, 41, 3527-3536.

[40] Sankaran, M. and Viswanathan, B. (2007) Hydrogen Storage in Boron Substituted Carbon Nanotubes. Carbon, 45, 1628-1635.

[41] Viswanathan, B. and Sankaran, M. (2009) Hetero-Atoms as Activation Centers for Hydrogen Absorption in Carbon Nanotubes. Diamond and Related Materials, 18, 429-432.

[42] Haque, E., Islam, M.M., Pourazadi, E., Hassan, M., Faisal, S.N., Roy, A.K., et al. (2015) Nitrogen Doped Graphene via Thermal Treatment of Composite Solid Precursors as a High Performance Supercapacitor. RSC Advances, 5, 30679-30686. https://doi.org/10.1039/C4RA17262K

[43] Zheng, C., Zhou, X.F., Cao, H.L., Wang, G.H. and Liu, Z.P. (2015) Nitrogen-Doped Porous Graphene-Activated Carbon Composite Derived from “Bucky Gels” for Super Capacitors. RSC Advances, 5, 10739-10745. https://doi.org/10.1039/C4RA13724H

[44] Li, N., Wang, Z., Zhao, K., Shi, Z., Gu, Z. and Xu, S. (2010) Large Scale Synthesis of N-Doped Multi-Layered Graphene Sheets by Simple Arc-Discharge Method. Carbon, 48, 255-259. 
[45] Oku, T. and Narita, I. (2002) Calculation of $\mathrm{H}_{2}$ Gas Storage for Boron Nitride and Carbon Nanotubes Studied from the Cluster Calculation. Physica B: Condensed Matter, 323, 216-218.

[46] Ariharan, A., Viswanathan, B. and Nandhakumar, V. (2015) Hydrogen Sorption in Phosphorous Substituted Carbon Material. Indian Journal of Chemistry, 54A, 14231433.

[47] Zhu, Z., Hatori, H., Wang, S. and Lu, G. (2005) Insights into Hydrogen Atom Adsorption on and the Electrochemical Properties of Nitrogen-Substituted Carbon Materials. The Journal of Physical Chemistry B, 109, 16744-16749. https://doi.org/10.1021/jp051787o

[48] Kim, G., Jhi, S.-H. and Park, N. (2008) Effective Metal Dispersion in Pyridinelike Nitrogen Doped Graphenes for Hydrogen Storage. Applied Physics Letters, 92, Article ID: 013106. https://doi.org/10.1063/1.2828976

[49] Wang, L., Lee, K., Sun, Y.-Y., Lucking, M., Chen, Z., Zhao, J.J. and Zhang, S.B. (2009) Graphene Oxide as an Ideal Substrate for Hydrogen Storage. ACS Nano, 3, 2995-3000. https://doi.org/10.1021/nn900667s

[50] Geng, D., Chen, Y., Chen, Y., Li, Y., Li, R., Sun, X., Ye, S. and Knights, S. (2011) High Oxygen-Reduction Activity and Durability of Nitrogen-Doped Graphene. Energy \& Environmental Science, 4, 760-764. https://doi.org/10.1039/c0ee00326c

[51] Choi, H.-J., Jung, S.-M., Seo, J.-M., Chang, D.W., Dai, L. and Baek, J.-B. (2012) Graphene for Energy Conversion and Storage in Fuel Cells and Super Capacitors. Nano Energy, 1, 534-551.

[52] Ning, R., Ge, C., Liu, Q., Tian, J., Asiri, A.M., Alamry, K.A., Li, C.M. and Sun, X. (2014) Hierarchically Porous N-Doped Carbon Nanoflakes: Large-Scale Facile Synthesis and Application as an Oxygen Reduction Reaction Electrocatalyst with High Activity. Carbon, 78, 60-69.

[53] Qian, Y., Du, P., Wu, P., Cai, C. and Gervasio, D.F. (2016) The Chemical Nature of Catalytic Act ive Sites for the Oxygen Reduction Reaction on Nitrogen-Doped Carbon-Supported Non-Noble-Metal Catalysts. The Journal of Physical Chemistry C, 120, 9884-9896. https://doi.org/10.1021/acs.jpcc.6b02670

[54] Jiang, Z., Zhao, X., Tian, X., Luo, L., Fang, J., Gao, H. and Jiang, Z.-J. (2015) Hydrothermal Synthesis of Boron and Nitrogen Codoped Hollow Graphene Microspheres with Enhanced Electrocatalytic Activity for Oxygen Reduction Reaction. ACS Applied Materials \& Interfaces, 7, 19398-19407. https://doi.org/10.1021/acsami.5b05585

[55] Hummers, W.S. and Offeman, R.E. (1958) Preparation of Graphitic Oxide. Journal of the American Chemical Society, 80, 1339-1339. https://doi.org/10.1021/ja01539a017

[56] Chaudhari, N.K., Song, M.Y. and Yu, J.-S. (2014) Heteroatom-Doped Highly Porous Carbon from Human Urine. Scientific Reports, 4, Article No. 5221.

[57] Geng, D., Yang, S., Zhang, Y., Yang, J., Liu, J., Li, R., et al. (2011) Nitrogen Doping Effects on the Structure of Graphene. Applied Surface Science, 257, 9193-9198.

[58] Zheng, F., Yang, Y. and Chen, Q. (2014) High Lithium Anodic Performance of Highly Nitrogen-Doped Porous Carbon Prepared from a Metal-Organic Framework. Nature Communications, 5, Article No. 5261.

[59] Jiménez, V., Ramírez-Lucas, A., Sánchez, P., Valverde, J.L. and Romero, A. (2012) Hydrogen Storage in Different Carbon Materials: Influence of the Porosity Development by Chemical Activation. Applied Surface Science, 258, 2498-2509.

[60] Hu, J., Yang, P. and Lieber, C.M. (1998) Nitrogen-Driven Transformation in Car- 
bon Nitride Materials. Applied Surface Science, 57, 185-188.

[61] Chen, Y., Xie, B., Ren, Y., Yu, M., Qu, Y., Xie, T., Zhang, Y. and Wu, Y. (2014) Designed Nitrogen Doping of Few-Layer Graphene Functionalized by Selective Oxygenic Groups. Nanoscale Research Letters, 9, 646-646.

https://doi.org/10.1186/1556-276X-9-646

[62] Liu, S., Dong, Y., Zhao, C., Zhao, Z., Yu, C., Wang, Z., et al. (2015) Nitrogen-Rich Carbon Coupled Multifunctional Metal Oxide/Graphene Nanohybrids for LongLife Lithium Storage and Efficient Oxygen Reduction. Nano Energy, 12, 578-587.

[63] Cançado, L.G., Jorio, A., Ferreira, E.H.M., Stavale, F., Achete, C.A., Capaz, R.B., Moutinho, M.V.O., Lombardo, A., Kulmala, T.S. and Ferrari, A.C. (2011) Quantifying Defects in Graphene via Raman Spectroscopy at Different Excitation Energies. Nano Letters, 11, 3190-3196. https://doi.org/10.1021/nl201432g

[64] L.M. Malard, M.A. Pimenta, G. Dresselhaus, M.S. Dresselhaus, (2009) Raman spectroscopy in graphene, Physics Reports, 473, 51-87.

[65] Song, X., Lin, L., Rong, M., Wang, Y., Xie, Z. and Chen, X. (2014) Mussel-Inspired, Ultralight, Multifunctional 3D Nitrogen-Doped Graphene Aerogel. Carbon, 80, 174-182.

[66] Sing, K.S.W. (1985) Reporting Physisorption Data for Gas/Solid Systems with Special Reference to the Determination of Surface Area and Porosity. Pure and Applied Chemistry, 57, 603-619.

[67] Zhao, Y., Liu, M., Gan, L., Ma, X., Zhu, D., Xu, Z. and Chen, L. (2014) Ultramicroporous Carbon Nanoparticles for the High-Performance Electrical Double-Layer Capacitor Electrode. Energy \& Fuels, 28, 1561-1568. https://doi.org/10.1021/ef402070j

[68] Yuan, H., Hou, Y., Wen, Z., Guo, X., Chen, J. and He, Z. (2015) Porous Carbon Nanosheets Codoped with Nitrogen and Sulfur for Oxygen Reduction Reaction in Microbial Fuel Cells. ACS Applied Materials \& Interfaces, 7, 18672-18678. https://doi.org/10.1021/acsami.5b05144

[69] Qu, L., Liu, Y., Baek, J.-B. and Dai, L. (2010) Nitrogen-Doped Graphene as Efficient Metal-Free Electrocatalyst for Oxygen Reduction in Fuel Cells. ACS Nano, 4, 13211326. https://doi.org/10.1021/nn901850u

[70] Zhou, X., Bai, Z., Wu, M., Qiao, J. and Chen, Z. (2015) 3-Dimensional Porous N-Doped Graphene Foam as a Non-Precious Catalyst for the Oxygen Reduction Reaction. Journal of Materials Chemistry A, 3, 3343-3353. https://doi.org/10.1039/C4TA06538G

[71] Shi, L., Liu, S., He, Z. and Shen, J. (2014) Nitrogen-Doped Graphene: Effects of Nitrogen Species on the Properties of the Vanadium Redox Flow Battery. Electrochimica Acta, 138, 93-100.

[72] Long, D., Li, W., Ling, L., Miyawaki, J., Mochida, I. and Yoon, S.-H. (2010) Preparation of Nitrogen-Doped Graphene Sheets by a Combined Chemical and Hydrothermal Reduction of Graphene Oxide. Langmuir, 26, 16096-16102.

https://doi.org/10.1021/la102425a

[73] Kan, K., Wang, L., Yu, P., Jiang, B., Shi, K. and Fu, H. (2016) 2D Quasi-Ordered Nitrogen-Enriched Porous Carbon Nanohybrids for High Energy Density Supercapacitors. Nanoscale, 8, 10166-10176.

[74] Gao, H., Song, L., Guo, W., Huang, L., Yang, D., Wang, F., Zuo, Y., Fan, X., Liu, Z. and Gao, W. (2012) A Simple Method to Synthesize Continuous Large Area Nitrogen-Doped Graphene. Carbon, 50, 4476-4482.

[75] Yang, S.J., Cho, J.H., Oh, G.H., Nahm, K.S. and Park, C.R. (2009) Easy Synthesis of 
Highly Nitrogen-Enriched Graphitic Carbon with a High Hydrogen Storage Capacity at Room Temperature. Carbon, 47, 1585-1591.

[76] Marton, D., Boyd, K., Al-Bayati, A., Todorov, S. and Rabalais, J. (1994) Carbon Nitride Deposited Using Energetic Species: A Two-Phase System. Physical Review Letters, 73, 118. https://doi.org/10.1103/PhysRevLett.73.118

[77] Mao, Y., Duan, H., Xu, B., Zhang, L., Hu, Y., Zhao, C., Wang, Z., Chen, L. and Yang, Y. (2012) Lithium Storage in Nitrogen-Rich Mesoporous Carbon Materials. Energy \& Environmental Science, 5, 7950-7955. https://doi.org/10.1039/c2ee21817h

[78] Sheng, Z.-H., Shao, L., Chen, J.-J., Bao, W.-J., Wang, F.-B. and Xia, X.-H. (2011) Catalyst-Free Synthesis of Nitrogen-Doped Graphene via Thermal Annealing Graphite Oxide with Melamine and Its Excellent Electrocatalysis. ACS Nano, 5, 4350 4358. https://doi.org/10.1021/nn103584t

[79] Zhu, T., Zhou, J., Li, Z., Li, S., Si, W. and Zhuo, S. (2014) Hierarchical Porous and N-Doped Carbon Nanotubes Derived from Polyaniline for Electrode Materials in Supercapacitors. Journal of Materials Chemistry A, 2, 12545-12551. https://doi.org/10.1039/C4TA01465K

[80] Ariharan, A., Viswanathan, B. and Nandhakumar, V. (2016) Phosphorous Doped Porous Carbon Derived from Newly Growing Paste of Ficus benghalensis as Hydrogen Storage Material. Indian journal of chemistry, 55A, 649-656.

[81] Ariharan, A., Viswanathan, B. and Nandhakumar, V. (2016) Heteroatom Doped Multi-Layered Graphene Material for Hydrogen Storage Application. Graphene, 5, 39-50. https://doi.org/10.4236/graphene.2016.52005

[82] Zhang, Z. and Cho, K. (2007) Ab Initio Study of Hydrogen Interaction with Pure and Nitrogen-Doped Carbon Nanotubes. Physical Review B, 75, Article ID: 075420. https://doi.org/10.1103/PhysRevB.75.075420

\section{Submit or recommend next manuscript to SCIRP and we will provide best service for you:}

Accepting pre-submission inquiries through Email, Facebook, LinkedIn, Twitter, etc. A wide selection of journals (inclusive of 9 subjects, more than 200 journals)

Providing 24-hour high-quality service

User-friendly online submission system

Fair and swift peer-review system

Efficient typesetting and proofreading procedure

Display of the result of downloads and visits, as well as the number of cited articles

Maximum dissemination of your research work

Submit your manuscript at: http://papersubmission.scirp.org/

Or contact graphene@scirp.org 